
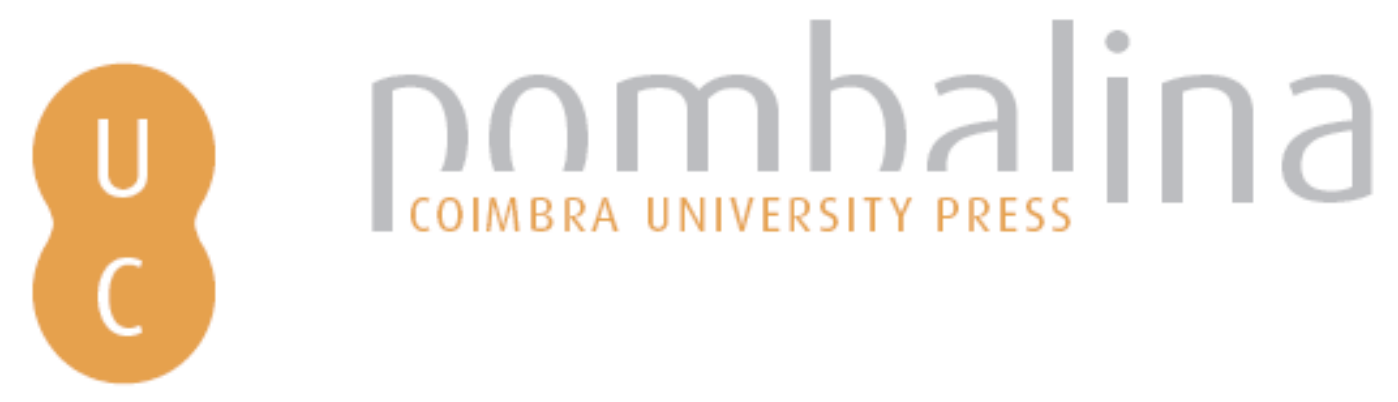

\title{
Discursividade e legitimação do Direito: comunicação, justiça e deliberação democrática
}

\author{
Autor(es): $\quad$ Ferreira, Gil Baptista \\ Publicado por: Imprensa da Universidade de Coimbra \\ URL \\ persistente: URI:http://hdl.handle.net/10316.2/38566 \\ DOI: DOl:http://dx.doi.org/10.14195/978-989-26-0770-2_5 \\ Accessed : $\quad$ 26-Apr-2023 08:03:27
}

A navegação consulta e descarregamento dos títulos inseridos nas Bibliotecas Digitais UC Digitalis, UC Pombalina e UC Impactum, pressupõem a aceitação plena e sem reservas dos Termos e Condições de Uso destas Bibliotecas Digitais, disponíveis em https://digitalis.uc.pt/pt-pt/termos.

Conforme exposto nos referidos Termos e Condições de Uso, o descarregamento de títulos de acesso restrito requer uma licença válida de autorização devendo o utilizador aceder ao(s) documento(s) a partir de um endereço de IP da instituição detentora da supramencionada licença.

Ao utilizador é apenas permitido o descarregamento para uso pessoal, pelo que o emprego do(s) título(s) descarregado(s) para outro fim, designadamente comercial, carece de autorização do respetivo autor ou editor da obra.

Na medida em que todas as obras da UC Digitalis se encontram protegidas pelo Código do Direito de Autor e Direitos Conexos e demais legislação aplicável, toda a cópia, parcial ou total, deste documento, nos casos em que é legalmente admitida, deverá conter ou fazer-se acompanhar por este aviso.

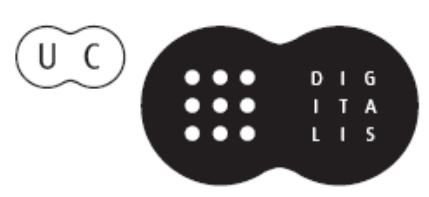



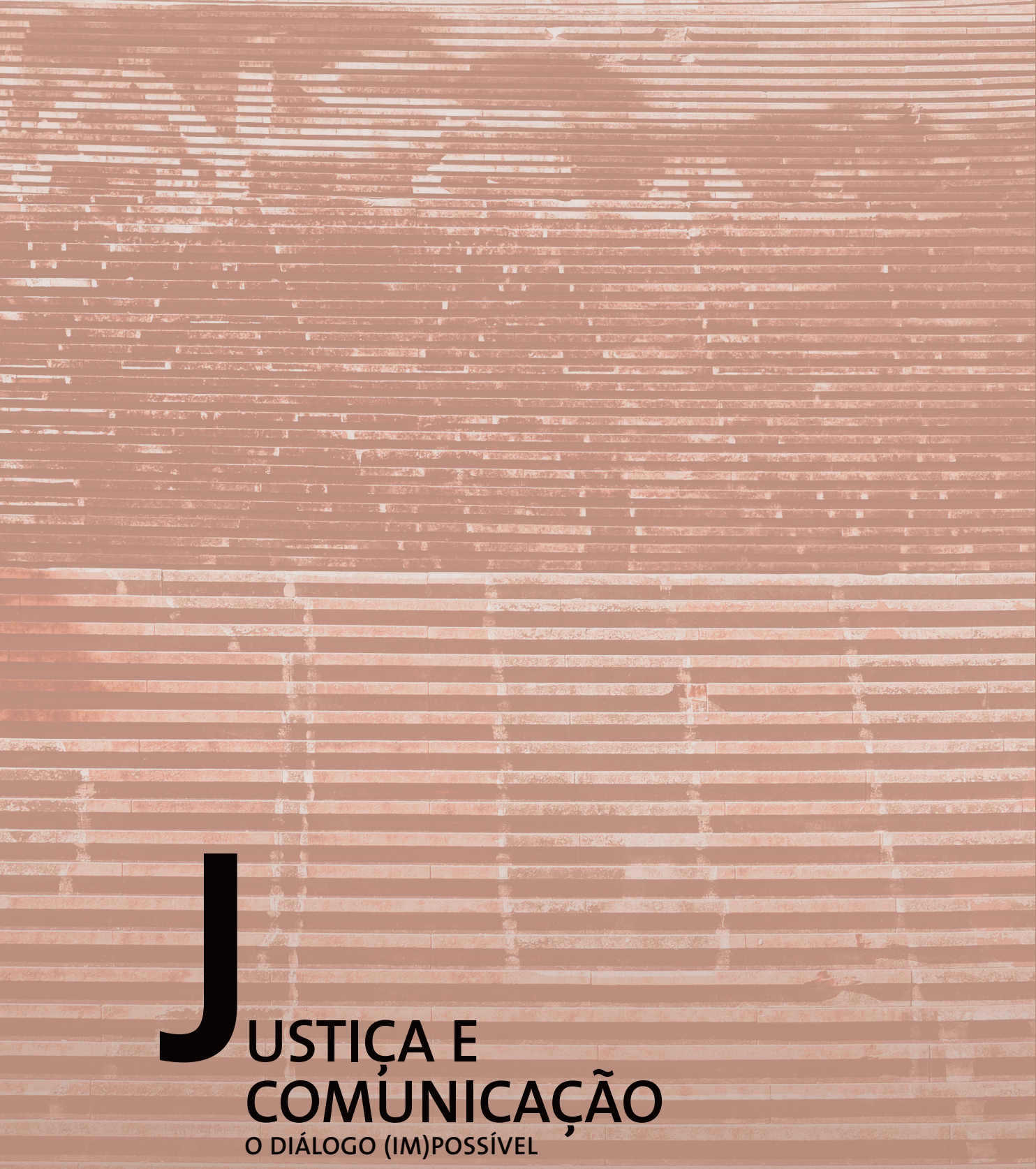

Rita Basilio Simões

Carlos Camponez

Ana Teresa Peixinho

ORGANIZAÇÃO 


\section{Gil Baptista Ferreira}

(Instituto Politécnico de Coimbra)

\section{I S C URS IVIDADE E LEGITIMAÇÃO DO D IREITO \\ C O M U N I CAÇ ÃO, JUST I ÇA E}

D ELI B E R Ç ÃO D EMOCRÁTICA

É sabido que um dos requisitos funcionais do estado de Direito é a especialização na produção de decisões que envolvam toda a comunidade, mantendo, para esse fim, uma relação reflexiva com os sistemas e as formas de coordenação e integração social. Nesta medida, um estado constitucional forte é condição necessária à garantia de justiça social e à institucionalização de direitos. Ao mesmo tempo, o Estado é o agente a quem cabe evitar distorções e patologias sociais que comprometam o reconhecimento jurídico da liberdade humana e a sua reificação através de relações juridicamente determinadas que, no seu funcionamento, reduzam o indivíduo a mero sujeito de Direito, num processo que desacreditaria a própria ideia emancipadora da democracia.

Deste modo, é hoje aceite, de modo pacífico, a ideia de que "todos os cidadãos possuem o mesmo direito de tomar parte e de determinar o resultado de processos constitucionais que estabelecem as leis com as quais devem concordar" (Rawls, 1971: 221). Contudo, se o requisito de justiça, segundo John Rawls, é determinado pelo facto de que todos têm uma oportunidade justa de sustentar um argumento público e de influenciar o resultado de decisões, um dos principais problemas que se coloca, neste âmbito, é o de decidir o lugar e o alcance da opinião e da vontade dos cidadãos no modo como nas democracias são produzidas as decisões políticas, os corpos legislativos e os procedimentos legais.

É este o tema do presente texto. De forma mais concreta, a questão central que o anima pode ser resumida do modo seguinte: sob que condi- 
ções é de esperar que procedimentos decisórios democráticos produzam resultados políticos aceites como justos? O que implica outro questionamento, mais abrangente, que igualmente se procurará desenvolver: que modelo de democracia pode promover o ajustamento entre, por um lado, os cidadãos, as suas opiniões e vontades (e, deste modo, os seus problemas, as suas formulações e as suas preferências) e, por outro lado, o sistema que produz decisões obrigatórias para todos os membros da comunidade política? Tomando como ponto de partida a ideia normativa de que devem haver processos coletivos por meio dos quais se formam a opinião e a vontade geral (para usar os termos propostos por Jürgen Habermas), propomos uma tentativa de resposta às questões anteriores sob o enquadramento do modelo deliberativo de democracia, enquanto teoria capaz de elucidar a lógica das práticas democráticas já existentes e os princípios nelas implícitos, e que procura dar conta dos mecanismos mediante os quais a opinião pública e a vontade geral são justificadas, e a produção da decisão política - e, em particular, da Lei - obtém a sua legitimidade.

\section{Democracia deliberativa e definição de justiça}

À entrada na década de 90 do último século, a teoria política dedicada ao estudo da democracia sofreu aquilo que alguns designam como viragem deliberativa, que viria a marcar de modo decisivo o campo da teoria política democrática do presente início do século XXI. ${ }^{151}$ Com ênfase nos aspetos discursivos do processo político, e consagrando a ideia de esfera pública como palavra-chave incontornável em teoria social, os chamados deliberacionistas ocupam hoje um lugar central nas discussões sobre o significado da democracia, e o lugar que nela assume toda uma teoria política da comunicação que recupera temas como a formação discursiva da opinião e da vontade.

151 Apesar de os primeiros trabalhos com a expressão "democracia deliberativa" terem surgido nos anos 80, nomeadamente com Joseph Bessette (1980), Bernard Manin (1987) e Joshua Cohen (1989), apenas a partir da década seguinte esta tendência adquiriu lugar de destaque na agenda da teoria política. 
As raízes desta conceção de democracia não são recentes; de Aristóteles a Kant, Rousseau, Dewey ou Arendt, são muitas as figuras clássicas da história das ideias políticas que as várias tendências democrático-deliberativas apresentam como fonte de inspiração. O que é novo é a tentativa de apresentar uma alternativa distintamente deliberativa formulada a partir da tradição da teoria crítica (e, noutras versões, pelas teses liberais de Rawls), como resposta a uma realidade política e social marcada por um sistema capitalista crescentemente transnacional, por um sistema cultural que coloca em confronto tradições provenientes dos mais variados pontos do globo e por desenvolvimentos decisivos na noção de cidadania. Em consequência, a democracia deliberativa vem afirmar a necessidade de justificar decisões, sejam elas tomadas por cidadãos ou pelos seus representantes: espera-se que ambas as partes justifiquem as leis que imporiam uma à outra, enquanto pessoas livres e iguais que procuram os termos justos de cooperação. A base moral para este processo de justificação é simples: as pessoas não devem ser tratadas como meros objetos de legislação, como sujeitos passivos para serem governados, mas como agentes autónomos que fazem parte do governo da sua própria sociedade, direta ou indiretamente através dos seus representantes. Ora, em acordo com o modelo deliberativo, "uma importante forma pela qual estes agentes fazem parte é apresentando ou respondendo a motivos, ou solicitando que os seus representantes o façam, com o objetivo de justificar as leis sob as quais eles devem viver juntos" (cf. Gutmann e Thompson, 2007: 20).

Na medida em que justificações públicas de leis e políticas têm de ser estruturadas em função de conceções de bem comum, à deliberação pública cabe o objetivo de calcular os detalhes dessas conceções, e aplicá-los a questões particulares da vida pública (cf. Cohen, 2009: 87). Como refere Habermas (1996), comummente considerado a principal referência teórica deste modelo, ${ }^{152}$ o ideal deliberativo procura justamente adaptar as instituições políticas às sociedades complexas, descentralizadas, pluralistas,

152 Seguimos a opinião de Guttmann e Thompson, para quem "mais que qualquer outro teórico, Jürgen Habermas é responsável por trazer de volta a ideia da deliberação aos nossos tempos, e por lhe dar uma base mais cuidadosamente democrática" (cf. 2004: 25), não deixando de reconhecer a influência tutelar, para outros pensadores deliberativos, de John Rawls. 
multiculturais, que as formas tradicionais, dominantes, de representação política tendem a trair. Assim, Rawls e Habermas vieram mostrar que as relações entre moral, Direito e política não apenas se tornaram problemáticas proporcionalmente às diferenciações cada vez mais complexas entre níveis jurídicos, políticos e económicos das instituições sociais, mas que a própria conceção de um Estado democrático de Direito carece de uma legitimação satisfatória nos seus fundamentos constitucionais.

Nos seus traços essenciais, o modelo deliberativo assenta sobre um conjunto de pressupostos que o distinguem das teorias concorrentes. ${ }^{153}$ No centro dos seus interesses estão os processos pelos quais são formadas a opinião e a vontade coletiva, enquanto modo de legitimação da decisão política em geral, e da Lei ou das políticas públicas em particular. Joseph Schumpeter, numa obra clássica da teoria política dos anos 40 do último século, Capitalismo, Socialismo e Democracia, colocava a pergunta: é possível que o povo tome decisões? Para Schumpeter, o processo democrático é justamente o contrário: "um método político, isto é, um certo tipo de arranjo institucional para se chegar a decisões políticas e administrativas" (1994: 242). Nessa medida, antes da viragem para a deliberação, o ideal democrático era definido sobretudo em termos de agregação de interesses ou preferências individuais em decisões coletivas por meio de instrumentos como as eleições e de princípios como a representação política - em acordo com uma conceção de democracia representativa liberal, que reserva ao cidadão a tarefa de escolher periodicamente os seus representantes, não necessitando para isso de se envolver diretamente em processos de deliberação ou tomada de decisões.

A metáfora do "mercado político" é usada neste contexto, uma vez que os cidadãos escolhem entre as ofertas que lhes são apresentadas na procura da maior satisfação dos seus interesses pessoais. Em acordo com esta perspetiva, os problemas políticos nas sociedades complexas são entendidos enquanto problemas de "governamentalidade" - para os quais as respostas deverão ser encontradas em dispositivos estruturais e formais,

153 Tomamos como referência a simplificação proposta por Ian Shapiro (1999), que identifica duas grandes correntes, a "agregativa" (hegemónica) e a "deliberativa". 
como o sistema partidário e a representação política, a agregação de interesses e os problemas de coordenação social em geral. De igual modo, perante conflitos de outra ordem, do campo ético-moral ou do plano da justiça social, a resposta é obtida através do voto - cabendo aos indivíduos a tarefa de encontrar (ou constituir-se enquanto tal) um representante no espaço público formal decisório. Se todos têm oportunidade equitativa para exprimir as suas preferências acerca das decisões em causa, os resultados do processo democrático tenderão a corresponder aos interesses de uma maioria, ou pelo menos de uma pluralidade de indivíduos.

É como contestação a esta ideia de política que surge a democracia deliberativa, alegando que procedimentos justos - como o serão as diferentes formas de agregação de preferências e a "contagem de cabeças" pelo povo - podem levar a resultados injustos. Ao negar, entre outros aspetos, o carácter privado da formação das preferências agregadoras, pretende-se enfatizar a necessidade do debate público e da troca de razões sobre o que é justo. Contra a preferência por modelos "de mercado" estreitamente concebidos, John Elster observa que "a tarefa da política não é só eliminar a ineficiência, mas também criar justiça - um objetivo diante do qual a agregação de preferências pré-políticas é um meio quase incongruente" (1989: 111). Deste modo, e em alternativa, a deliberação é, em diferentes níveis de governo e em contextos políticos variados, o meio mais legítimo para resolver os conflitos de princípios sobre questões de justiça social, tornando assim a tomada de decisão que resulta da deliberação entre cidadãos livres e iguais a forma de justificação mais defensável (cf. Guttmann e Thompson, 2007). Uma ideia que encontra complemento nas palavras de Manin (1987: 352): "Uma vez que as decisões políticas são caracteristicamente impostas a todos, parece razoável buscar, como condição essencial para a legitimidade, a deliberação de todos ou, mais precisamente, o direito de todos a participarem na deliberação.”

Sem no entanto ignorar os aspetos formais da tomada de decisão, o modelo deliberativo opõe às perspetivas dominantes a noção de debate racional enquanto paradigma do procedimento político. Na génese da formulação teórica deste modelo está o contributo do próprio Manin, 
acima citado, ao distinguir dois sentidos de deliberação - como "processo de discussão" e como "decisão" - e ao fazer depender teórica e praticamente o segundo sentido do primeiro. A partir daqui, terá sido possível a Joshua Cohen formular aquela que é uma das primeiras explicitações do modelo: "A conceção de democracia deliberativa está organizada em torno de um ideal de justificação política. De acordo com este ideal, justificar o exercício do poder coletivo é proceder com base na argumentação pública livre entre iguais. Uma democracia deliberativa institucionaliza este ideal" (Cohen, 1997: 412).

Entendido deste modo, o Direito reivindica a sua natureza verdadeiramente democrática na medida em que incorpora princípios essenciais do ideário democrático, como a igualdade política de todos os participantes e a sensibilidade ao ideário público, sustentando a sua autoridade e a sua legitimidade em formas de razão pública. Nos capítulos 3 e 9 de Between Facts and Norms (1996), Habermas resume aquela que é a tese central da sua teoria da democracia - e que se reveste de grande utilidade para os nossos propósitos neste texto - com o objetivo de mostrar a relação interna entre o Estado de Direito (rule of the law) e a democracia, onde o recurso ao modelo deliberativo constitui o modo de garantir a autonomia privada e pública de sujeitos legais, no âmbito do processo político de legitimação. Implícita nesta tese, está uma ideia forte: o Direito, enquanto poder legítimo (coação ou violência institucionalizadas) não é plenamente legitimado sem o recurso a uma normatividade gerada num agir comunicativo e numa razão comunicativa. Assim, de certo modo, apenas é democraticamente legitimada a Lei que emergir de um processo discursivo de formação da opinião e da vontade coletivas, levado a cabo por cidadãos em situação de equidade de direitos.

A questão que verdadeiramente se coloca é a da possibilidade de um espaço público permitir aos atores da sociedade civil desafiarem os poderes (legislativo, político, económico...), isto é, de filtrarem de um modo crítico todo o espectro de razões, temas e valores canalizados por influências exercidas a partir do exterior. Concretamente, Habermas refere-se aos casos em que os atores da sociedade civil enunciam as suas reivindicações, seja para negociar valores e novas formas de comunicação, 
representação e reconhecimento enquanto grupos que são vítimas de injustiça social, seja para ampliar o debate público sobre direitos, seja ainda para exigir a prestação de contas em relação a atos e decisões de representantes políticos. A partir das ideias de participação política e da necessária extensão das arenas da vida pública, na sua vertente mais habermasiana, a deliberação baseia-se no pressuposto de que a participação democrática só pode ser conseguida se incluir na sua base normativa a prática do diálogo político equitativo. É a partir desta perspetiva que uma conceção deliberativa de democracia se apresenta como resposta conceptual consistente à transformação de um espaço público que reivindica fazer-se ouvir e afirmar-se, fundamentada na capacidade detida por todos os cidadãos de deliberar racionalmente sobre as decisões coletivas que lhes dizem respeito.

A partir do elemento democrático, enquanto modo de participação na tomada de decisão coletiva por todos os afetados pelas decisões, e do elemento deliberativo, relativo à inclusão nos processos de tomada de decisão dos participantes "comprometidos com os valores de racionalidade e imparcialidade" (Elster, 1998: 8), o modelo deliberativo defende a possibilidade de fundamentar a autoridade e a legitimação das leis em alguma forma de razão pública, redefinindo-as como poder gerado comunicacionalmente, extensível não apenas às componentes formais de deliberação (orientadas para a tomada de decisão) como às informais, resultantes do intercâmbio discursivo feito no espaço público.

O resultado deve ser público não apenas no sentido em que materializa um consenso de ideias ou uma decisão que vincula e obriga todas as vontades no interior de uma comunidade, mas também na medida em que reflete um processo de produção resultante de um investimento coletivo. É esta característica que permite o encaixe entre a dimensão factual e a dimensão normativa da Lei, para usarmos os termos próprios do modelo habermasiano. Em suma: a opinião e a vontade coletiva, que formam a comunidade política e se materializam como opinião pública e como decisão política legislativa, devem ser produzidas mediante a participação de todos os cidadãos que o desejem, em situação de igualdade de oportunidades, como modo de garantir a sua legitimidade. 


\section{Como formalizar a comunicação pública?}

O instrumento básico de mediação é um sistema de duas vias (two-track), na medida em que procura articular as deliberações orientadas para a decisão com os procedimentos informais no espaço público: o que inclui tanto o poder político nas suas formas institucionais como os cidadãos - num processo em que as instituições "formais", como o Parlamento, proporcionam um enquadramento institucional para uma comunicação mais vasta, descentrada, anónima, dispersa pela esfera pública, e envolvendo todos os cidadãos. Uma via é institucional; a outra, não. A formação política da vontade inicia-se nas esferas públicas não-institucionais, constituídas por redes de comunicação espontâneas e interconectadas da sociedade civil, responsáveis não apenas pela identificação dos novos problemas sociais como também pela elaboração discursiva de tais problemas, pela articulação de identidades coletivas e pela seleção dos melhores argumentos apresentados, para constituir a partir daqui verdadeiras pautas políticas destinadas às instituições político-decisórias, e exigir nestas a devida representação.

De um lado, há a institucionalização legal do processo de formação da opinião e da vontade, que resulta em "decisões a respeito de políticas e de leis" (Habermas, 1996: 187). Este processo deve ocorrer mediante formas de interação discursiva, através de instâncias de argumentação que filtrem razões, informações e contributos de um modo tal que o resultado final possa gozar do estatuto de aceitabilidade racional. Em termos práticos, a argumentação ou discussão estabelece relações de entendimento recíproco, isentos de violência, atravessados pela força geradora da liberdade comunicativa. É neste processo de formação da opinião e da vontade que, segundo Habermas, se produz a Lei, num meio tipicamente composto pelos agentes parlamentares. Pode assim dizer-se que esta via de formação de opinião e vontade, materializada em leis e políticas, ocorre mediante "deliberações institucionalizadas" (Habermas, 1996: 225).

Do outro lado, encontra-se a forma não institucionalizada (informal) de formação da opinião e da vontade públicas. Noutros termos, referimo-nos aqui à noção de "esfera pública", entendida enquanto âmbito ou 
espaço onde se verifica a livre flutuação de questões, de informações e de argumentos provenientes das experiências quotidianas dos sujeitos. Deste modo, se dos debates institucionalizados resultam leis e políticas, na comunicação pública informal concretizam-se a opinião e a vontade públicas. A esfera pública é assim entendida como uma arena discursiva livre, onde circulam argumentos e pontos de vista para gerar uma opinião pública, tão dispersa (não institucionalizada) pela esfera civil que, na prática, é abstrata e anónima (cf. Bohman, 1996: 178).

Chegados a este ponto, é possível verificar que, a partir deste modelo, nem há necessidade de que o Direito seja submetido à democracia, nem que a democracia recue perante os ditames do Direito. De um lado, o Direito que emerge de um processo coletivo de produção é a pré-condição procurada e aceite pelos membros de uma comunidade política. Muito embora Habermas não o diga explicitamente, a deliberação institucionalizada é o modo fundamental de funcionamento das diversas instâncias judiciais, assim como das diversas estruturas parlamentares. Por outro lado, a democracia é vista como o modo pelo qual o indivíduo exerce autonomia política, o que é garantido pela participação plena dos membros da comunidade política no processo em que são formadas a opinião e a vontade coletivas, materializadas no Direito.

A compatibilidade entre os exigentes requisitos da comunicação pública na formação da opinião e da vontade coletivas, e o facto de a opinião pública não ser um sistema institucionalizado para produzir leis nem políticas, é obtida por meio de um conjunto de exigências normativas, próprias de um modelo discursivo de democracia. O objetivo dessas exigências é assegurar que a opinião gerada na esfera pública influencie os resultados do processo de produção de decisão política nas esferas parlamentares. Por se basear numa teoria discursiva, o êxito de um processo deliberativo depende "da institucionalização dos correspondentes procedimentos e condições de comunicação, bem como da interação dos procedimentos deliberativos institucionalizados com opiniões públicas informalmente desenvolvidas (Habermas, 1996: 298). Por isso, é uma teoria explicitamente normativa e procedimental da democracia, centrada no respeito pelo requisito essencial da legitimidade dos proces- 
sos democráticos - legitimidade dependente, por sua vez, da observação do conjunto de procedimentos imparciais de deliberação.

Como primeira instância, o teste de legitimidade consiste em verificar em que medida as deliberações institucionalizadas - e, entre elas, o modo parlamentar de produção de decisão - estão abertas a "aportes de informação, pressão dos problemas e ao potencial para estimular sugestões que podem ser encontradas na opinião pública" (Habermas, 1996: 225). A ideia de uma "esfera pública" de formação da opinião, debate, deliberação e contestação entre cidadãos, grupos, organizações e movimentos é essencial neste processo. A partir dela, os direitos humanos civis e políticos fundamentais - presentes na Constituição da maior parte dos governos democráticos - não estão nunca realmente "fora da agenda" da discussão pública e do debate. Muito embora não seja possível mudar esses direitos sem o uso de procedimentos políticos, cívicos e jurídicos extremamente elaborados, o seu sentido, a sua extensão e a sua jurisdição encontram-se sempre em disputa.

Concluindo: o princípio que nos importa sublinhar é o de que formas institucionalizadas de deliberação necessitam de possuir vínculos com a construção informal de opinião que se dá na esfera pública. Torna-se assim imprescindivel a existência de uma base normativa para a decisão legislativa: uma base que se apresenta como uma espécie de cristalização da "soberania civil" no poder dos discursos públicos. Noutros termos: é crucial articular a autonomia privada de indivíduos que perseguem os seus projetos de felicidade com a autonomia pública que garante o bem comum, tal como o sugeriam as ideias de vontade geral rousseauniana e de soberania popular.

Ora, a partir do momento em que aceitamos o ideal de um sistema justo de cooperação, torna-se necessária igualmente a existência de instituições políticas que se lhe adequem, isto é, torna-se necessário incorporar na "estrutura básica da sociedade um procedimento político efetivo que espelhe nessa estrutura a representação justa das pessoas" (Rawls, 1982: 45). Esse procedimento pode ser definido do modo seguinte: só podem ser consideradas válidas (isto é, moralmente vinculativas) aquelas normas (isto é, regras gerais de ação e arranjos institucionais) que possam receber a concordância de todos os afetados pelas suas consequências, 
se tal acordo for alcançado como resultado de um processo de deliberação com as seguintes características: 1) a participação na deliberação é regulada por normas de igualdade e simetria; todos possuem as mesmas possibilidades de iniciar atos de fala, de questionar, interrogar e de abrir o debate; 2) todos possuem o direito de questionar os argumentos presentes no diálogo; 3) todos possuem o direito de introduzir argumentos reflexivos sobre as regras do procedimento discursivo e o modo pelo qual elas são aplicadas ou conduzidas (cf. Benhabib, 2009).

Nestes termos, a deliberação apresenta-se como o modelo conceptual e institucional adequado para teorizar a experiência democrática de sociedades complexas e para permitir a expressão da diferença sem fraturar a identidade do corpo político e sem subverter as atuais formas de soberania política (Benhabib, 2009). Quando conduzida de modo apropriado, toda a ação política democrática requer alguma forma de igualdade manifesta entre os cidadãos, e dá forma às identidades e aos seus interesses, de modo a contribuir para a formação de uma conceção pública do bem comum (cf. Cohen, 2009: 88). Ao aceitarmos que o ideal de justiça - enquanto resultado de processo justo - começa com a necessidade de um conjunto de princípios comuns, devemos considerar a necessidade de estes princípios serem trabalhados sob uma perspetiva de igualdade, em que cada pessoa é representada de forma justa (cf. Rawls, 1971: 222).

Foi referido acima que, se as minorias podem ser afastadas do espaço público e empurradas para as margens pelos mecanismos de agregação, a deliberação vem apresentar-se como forma de atrair e criar vínculos com essas margens. A ideia impraticável de uma assembleia de massa que delibera é, neste modelo, substituída por uma conceção de deliberação em associações múltiplas: é da rede destas formas múltiplas de associações, ligações e organizações que resulta uma "comunicação pública" anónima. O modelo de democracia deliberativa tem de privilegiar esse tipo de esfera pública de redes e associações de deliberação, contestação e argumentações mutuamente sobrepostas (cf. Benhabib, 2009: 119). Dentro e entre estas redes, é essencial a existência de debate público para esclarecer reciprocamente os interlocutores; a discussão encoraja os indivíduos e os grupos a articularem bons argumentos que defendam 
as suas causas, e a autocorrigirem os seus pontos de vista, de modo a que possam ser aceites pelos demais participantes. Através do discurso chegamos não propriamente à descoberta dos nossos reais interesses, mas a uma interpretação coletiva de como devemos entender os nossos interesses mais importantes: "Um sistema deliberativo, no seu melhor, permite que os seus participantes se compreendam melhor a si próprios e ao meio onde vivem. Ajuda a que os participantes se modifiquem a si e aos outros num melhor sentido, para si e para a sociedade" (Mansbridge, 1999: 210-11).

A democracia deliberativa pede, assim que os cidadãos se comprometam uns com os outros, em condições pautadas pelo respeito mútuo, com o propósito de encontrar termos de uma cooperação razoável. No que se refere ao âmbito deste trabalho, os cidadãos não possuem motivos suficientes para acreditar que sabem o que a justiça requer da sociedade como um todo sem se envolverem numa deliberação racional com os seus concidadãos. É pois a partir da interpretação coletiva obtida do modo descrito acima que as formas institucionalizadas de deliberação se acomodam com a opinião constituída informalmente na esfera pública. Deste modo, no seu melhor, e recorrendo aos termos de Joshua Cohen, a importância da ordem democrática não se limita a "obstruir a classe da legislação" (o que ocorre quando grupos se sentem excluídos dos canais de representação); além disso, a política democrática dá forma aos modos através dos quais os membros da sociedade se entendem a si mesmos e aos seus interesses (cf. Cohen, 2009: 88), e acaba por dar forma, igualmente, à construção das leis. Como tem vindo a ser sugerido, este é um processo de aprendizagem social do que procuram o bem comum e a justiça - um processo sustentado num discurso público que seleciona compreensões e pontos de vista, que questiona argumentos antes de estes se fortalecerem, enfraquecerem ou desaparecerem.

\section{A discursividade da (in)justiça}

Não obstante a importância inegável que possui no atual debate académico e político, têm vindo a ser identificados problemas na proposta 
da deliberação democrática, tanto no plano do refinamento teórico como na dimensão prática da sua aplicação, que não podem ser negligenciados. Sendo clara à generalidade da literatura a convicção de que a deliberação pode promover a justiça, é igualmente partilhada a perceção de que raramente a deliberação encontra as condições ideais que a definem, enquanto modelo teórico. Desde logo, os problemas identificados enformam a partir do difícil equilíbrio entre a realidade e a idealização, que resulta, inevitavelmente, em problemas de eficácia, mais nítidos em contextos transnacionais (onde se situam muitas das grandes questões contemporâneas) e de comunicação global.

Como foi exposto, para que a democracia não se reduza a um mero regime processualista de escolha de elites, é condição necessária a circulação de comunicação e de informação vinculada às estruturas comunicativas do mundo da vida, que traduza pretensões de validade que permitam a formação de uma opinião pública racional. Detendo-nos sobre o papel central da comunicação no cerne da deliberação, e se atendermos de forma mais atenta aos pressupostos teóricos antes enunciados, são várias as questões que se colocam - e os motivos de suspeição levantados. Na verdade, e como sugerem alguns críticos, e se as próprias condições sob as quais os cidadãos deliberam sobre o significado da justiça forem elas mesmas injustas?

Como tem sido abundantemente descrito, os meios de comunicação tradicionais, e mesmo os novos meios, foram incubados em ambientes sistémicos onde os media reguladores são o poder e o dinheiro - sendo difícil sustentar que neles o uso estratégico da linguagem seja completamente secundário (cf. Correia, 2005: 49). Como uma vasta literatura tem demonstrado, a influência mais ou menos subtil do poder administrativo e económico associada ao apelo à unidade implícito na teoria deliberativa (a orientação para um bem comum que acaba por se constituir em apelo implícito a "alinhar" pela cultura dominante), podem conduzir a que o processo político possa passar a ser entendido como formação democrática da vontade a partir de processos de conformação discursiva da opinião pública, absorvendo tanto o poder político nas suas formas institucionais como os cidadãos. Grandes desigualdades de poder político 
e de riqueza, enormes discrepâncias no acesso aos media e vastas diferenças no controlo da informação, dão muito mais poder a algumas pessoas que a outras no âmbito do processo deliberativo, mesmo que este decorra em acordo com os mais elevados padrões normativos (cf. Gutmann e Thompson, 2007: 58). É nesta medida que John Rawls sublinha a importância de a deliberação pública ser livre de influências não discursivas: caso contrário, a tomada de decisão é dominada por interesses corporativos e outros interesses organizados, que distorcem, quando não excluem, a discussão e a deliberação pública (cf. Rawls, 2001:183).

Também a investigadora norte-americana Lynn Sanders (1997) questiona a existência de troca livre e equitativa de argumentos no curso do próprio debate deliberativo. Partindo da verificação de diferentes padrões de participação, mostra que situações de domínio surgem sobretudo como função do estatuto e de atributos dele correlativos, com consequências nos resultados dos debates. Concretamente, "o discurso mantém-se sempre distorcido por vários fatores como, por exemplo, a própria relutância dos grupos oprimidos à discussão (incluindo as mulheres ou as minorias) e a forma fácil como os seus meios discursivos, quando existem, se desprezam" (Silveirinha, 2005: 158). É esta perceção que motiva os teóricos da natureza cognitiva da deliberação racional a considerarem que a deliberação promove um tipo particular de discurso e de ator em prejuízo de todo um conjunto de formas alternativas de expressão linguística. Sanders mostra, a este propósito, que em fóruns constituídos por uma diversidade de indivíduos de perfis sociológicos distintos os debates tendem a ser ganhos pelos mais competentes no tipo particular de procedimento que é o debate - a despeito da fundamentação racional dos argumentos. Como mostram outros, "na prática [deliberativa], a influência não é fácil de separar do poder" (Mansbridge, 1999: 225). Tomando em conta atributos como idade, género, elementos socioeconómicos ou etnia, Sanders constata a natureza discriminatória daquele que é o procedimento prático e normativo privilegiado dos democratas deliberativos - a participação.

Como foi já referido, numa sociedade justa as oportunidades políticas e os poderes necessitam de ser independentes da posição económica e 
social, e essa independência deve ser evidente (Cohen, 2009: 87). Contudo, há indicadores fortes de que as normas de deliberação mais frequentes nos debates que ocorrem em parlamentos, tribunais, nas universidades e, de um modo geral, nos diferentes espaços públicos, pelo facto de se suporem um determinado viés cultural, tendem a silenciar ou desvalorizar grupos ou pessoas que se expressem de determinado modo, ao mesmo tempo que privilegiam outros tipos de discurso - o discurso formal, de carácter geral, frio, desapaixonado e expresso em linguagem literal. $\mathrm{Na}$ esfera pública pode ser detetada desigualdade motivada não apenas pela subordinação/dependência económica ou política, "mas também por um sentido internalizado do direito que se tem de falar ou não falar, da desvalorização do estilo de discurso de alguns indivíduos e da elevação de outros" (Young, 1990: 370).

O questionamento que a partir daqui se levanta é se, estabelecidas as condições elementares para a deliberação ocorrer - garantir o acesso aos participantes -, poderão (conseguirão) os "públicos fracos" assumir-se como interlocutores na mais plena dimensão. Tomando como referência uma teoria ética do discurso, o respeito moral pela personalidade autónoma é uma norma fundamental da democracia, que implica que cada indivíduo tenha direitos simétricos para produzir vários atos de fala, para iniciar novos tópicos, ou para qualquer outro tipo de participação. O que será necessário, assim, será um modelo de democracia deliberativa adequado a condições de injustiça: um modelo que não siga a lógica circular segundo a qual "os processos ideias da democracia deliberativa conduzem a resultados justos porque a deliberação começa na linha de partida da justiça" (Young, 2000: 34). Concretamente: um modelo que situe a linha de partida em condições desiguais de entrada no processo deliberativo.

O modo mais saliente de enfrentar os problemas anteriores é proposto por toda a teoria da diferença, que a transcrição seguinte resume de modo cabal: "olhar a diferença - mesmo que profunda - como um recurso, não como um obstáculo ao acordo, já que este, sem compreensão, nem sequer chega a ser um acordo. (...) Na verdade, para acordarmos sobre normas que verdadeiramente respeitem diferentes pontos de vista, devemos, consciente e deliberadamente, procurar compreender os pontos 
de vista dos outros e para isso são necessários alguns procedimentos para as trocas comunicativas nas relações com os outros que os reconheçam nos seus próprios termos, nas suas necessidades específicas e particulares, perspetivas, sentimentos e desejos" (Silveirinha, 2005: 158). Ora, uma proposta como a anterior implica a introdução de um outro conceito chave - o conceito de solidariedade. Por sua vez, o que está em jogo na esfera da solidariedade é o reconbecimento social da singularidade individual, por oposição à igualdade generalizável que caracteriza o Direito.

Nesta medida, a relação entre as dimensões do Direito e da solidariedade é íntima: a solidariedade social, ao impulsionar e legitimar formas de individuação progressiva (por exemplo, premiando o esforço diferencial com prestígio social) contribui para o enriquecimento de práticas sociais passíveis de serem, num momento posterior, reconhecidas e integradas juridicamente. Assim, é a passagem da solidariedade para o Direito que permite a constante renovação do Direito e do horizonte normativo como um todo (cf. Honneth, 1995: 254-255). Por fim, e mantendo ainda a noção de justiça como horizonte fundamental, não é indiscutível que a igualdade manifesta dos cidadãos seja uma característica inalienável de um processo justo: a conceção pluralista da política democrática como sistema de intercâmbio, com uma representação justa para todos os grupos, parece um espelho igualmente bom do ideal de justiça. O que implica um modo apropriado de agir: proceder não procurando espelhar a justiça ideal na justiça dos arranjos políticos, mas, pelo contrário, proceder de modo a espelhar um sistema de deliberação ideal nas instituições sociais e políticas (cf. Cohen, 2009: 89-90).

Verificamos, deste modo, que mesmo sob condições injustas a deliberação pode dar um contributo mais positivo para eliminar a injustiça que os modelos alternativos, como a tomada de decisão pelas elites políticas (muitas vezes, a fonte do problema) ou a negociação entre grupos de interesse (que normalmente reproduzem as desigualdades predominantes). Importa sublinhar o facto de, em acordo com este modelo, o poder da razão ser menos ligado (ou potencialmente desligado) às distribuições de poder existentes - e por isso possuir o potencial de as questionar. 
Em termos práticos, resulta daqui que, quando as injustiças predominantes beneficiam um grupo social específico, a deliberação chama a atenção pública para esta perturbação (cf. Gutmann e Thompson, 2007: 59).

\section{Conclusão}

Uma analogia de Benhabib é esclarecedora sobre o ponto de chegada deste texto. Numa breve passagem, compara o debate democrático a um jogo de futebol, no qual, todavia, não há qualquer árbitro para interpretar as regras do jogo e a sua aplicação definitiva. Contrariamente ao que sucede num jogo de futebol normal, no jogo da democracia as regras, a sua interpretação e mesmo a posição do árbitro são essencialmente contestáveis - não porque os participantes possuam interesses particulares distintos, mas em torno de conceções alternativas do bem comum. No entanto, a contestação não significa, aqui, a completa anulação das regras, e muito menos o silêncio sobre elas. Com efeito, se quando direitos e liberdades fundamentais são violados o jogo da democracia é suspenso (dando lugar a um governo marcial, a uma ditadura ou a uma guerra civil), já quando a política democrática está em pleno funcionamento, é o debate sobre o significado desses direitos, os seus limites, força e alcance, que determina o que realmente é a política (cf. Benhabib, 2009: 128-129).

Do mesmo modo, também as condições normativas dos discursos - onde se encontram, genericamente, os direitos e as liberdades básicas - devem ser vistas como regras do jogo, que podem ser contestadas através do próprio jogo, mas somente a partir do momento em que os participantes aceitam jogar segundo os conteúdos dessas regras. É esta, em traços breves, a lógica das práticas democráticas existentes nas sociedades atuais, são estes os princípios implícitos no seu funcionamento e, em maior ou menor escala, é através de mecanismos como os descritos acima que a opinião pública e a vontade geral obtêm a sua justificação e a Lei recebe a sua legitimidade. É esta ainda a pertinência do modelo deliberativo, enquanto matriz teórica que fundamenta a legitimidade e a legitimação 
das leis em alguma forma de razão pública, redefinindo-as como poder gerado comunicacionalmente. Nesta medida, explicações e justificações públicas de leis e políticas têm que ser concebidas em termos de bem comum (e não como competição entre perspetivas restritas baseadas em interesses de grupo), e a deliberação pública deve ter como objetivo calcular o detalhe dessas conceções, e aplicá-lo a questões particulares da vida pública (cf. Cohen, 2009: 87).

Podemos por fim assumir que uma das teses centrais resume-se na igual primordialidade entre autonomia pública e autonomia privada, ou, noutros termos, na relação recíproca entre direitos públicos e soberania popular, com partida num mesmo princípio de discursividade. Deste modo, consideramos que o Direito é originado num princípio discursivo de conteúdo neutro, que vem exigir o consentimento dos interessados para a sua validação normativa. O que possui um significado muito claro e de natureza muito prática: a coesão entre direitos e soberania popular pode ser alcançada apenas pela institucionalização jurídico-constitucional de procedimentos de participação, relativos à formação de opinião e de vontade - procedimentos estes imbricados nas formas de democracia deliberativa.

Serão estes procedimentos a solução infalível para obter decisões justas? Os democratas deliberativos recusam a promessa de que a deliberação seja a panaceia, que possa, por si só, transformar maus resultados em bons; apenas sustentam que os seus procedimentos são melhores que as suas alternativas. Por outro lado, também uma decisão sem deliberação não é, necessariamente, uma decisão injusta - apenas será menos justificável do que poderia ter sido (cf. Gutmann e Thompson, 2007: 58).

São muitos os desafios que se colocam ao modelo deliberativo - sobretudo ao nível dos desenhos institucionais que pode inspirar -, ao mesmo tempo que algumas insuficiências lhe são apontadas. Detenhamo-nos numa das críticas mais comuns, aquela que refere a sua irrelevância utópica, e que considera que as sociedades modernas complexas, com as suas esferas de vida culturais, económicas, sociais e jurídicas altamente complexas, não podem ser nem nunca serão organizadas a partir das linhas sugeridas por um modelo de democracia deliberativa. Não cabe aqui refutar esta objeção em toda a amplitude - nomeadamente no que 
se refere à complexidade social que enforma as sociedades contemporâneas. Assumindo uma perspetiva orientada a partir de uma teoria política da comunicação, importará antes reverter o sentido da questão: uma tarefa que implica averiguar não se as práticas discursivas podem tornar-se a norma estruturante de sociedades complexas, mas antes até que ponto as sociedades complexas são ainda capazes de manter um governo assente em formas de discursividade democrática (cf. Benhabib, 2009: 134-5). 


\section{B I B L I O G R A F I A}

AFONSO, O. (2005). "Dever de reserva - O seu papel na jurisdição". In: AA VV, Balanço da reforma da acção executiva. Segredo de justiça e dever de reserva (Conselho Superior da Magistratura, II Encontro Anual - 2004). Coimbra: Coimbra Editora, pp. 147-154.

ALBINO, C. (2003). «Sim, a Ordem dos Jornalistas». In: Diário de Notícias, 2 de novembro.

AMSELEK, P. (1964). Méthode phénoménologique et théorie du droit. Paris: L.G.D. J.

ANTUNES, F. (1994). "Alta Autoridade está queimada». In: Jornal de Notícias, 14 de março.

AZNAR, H. (2005). Comunicação Responsável - A auto-regulação dos media. Porto: Porto Editora.

BARREIROS, J. A. (2005). "O dever de reserva nas profissões jurídicas». In: AA VV, Balanço da reforma da acção executiva. Segredo de justiça e dever de reserva (Conselho Superior da Magistratura, II Encontro Anual - 2004). Coimbra: Coimbra Editora, pp. 163-170.

BARTHES, R. (1984). O rumor da língua. Lisboa: Ed. 70, (trad. portuguesa).

BECKETT, K. e WESTERN, B. (2001). "Governing social marginality: welfare, incarceration and the transformation of state policy". In: Punishment and Society, 1, pp. 43-59.

BENHABIB, S. (2009). "Rumo a um modelo deliberativo de legitimidade democrática». In: MARQUeS, A. (ed.), A Deliberação Pública e suas Dimensões Sociais, Políticas e Comunicativas. Belo Horizonte: Autêntica Editora.

BERGEL, J-L. (1997). "Du concept de déontologie à sa consécration juridique». In: BERGEL, J-L, (org.), Droit et Déontologies Professionnelles. Aix-en-Provence: Librairie de l'Université.

BHATIA, V. K. (1993). Analysing Genre: Language Use in the Professional Setting. London: Longman.

BHATIA, V. K. (1994). Cognitive structuring in legislative provisions. In: GIBBONS, J. (ed.). Language and the Law. London: Longman.

BHATIA, V. K. (2010). Legal writing: specificity. Specification in legislative writing: accessibility, transparency, power and control. In: Coulthard, M. e Johnson, A. (eds.) 2010. The Routledge Handbook of Forensic Linguistics. London: Routledge.

BIRESSI, A. e NUNN, H. (2003). "Video justice: crimes of violence in social/media space». In: Space \& Culture, 6 (3): pp. 276-291.

BOBBIO, N. (1982). A teoria das formas de governo. Brasília: UnB.

BOBBIO, N. (2000). O futuro da democracia. São Paulo: Paz e Terra.

BOHMAN, J. (2000). "The division of Labor in Democratic Discourse: Media, Experts, and Deliberative democracy». In: Chambers, S. and Costain, A. N. (org). Deliberation, Democracy and the Media. Maryland: Rowman \& Littlefield Publishers. 
BOTTOMS, A. E. (1995). «The philosophy and politics of punishment and sentencing». In: Clakson, C. and Morgan, R. (eds.). The Politics of Sentencing Reform. Oxford: Clarendon Press.

BRES, J. (2005). "Savoir de quoi on parle: dialogue, dialogal, dialogique; dialogisme, polyphonie...» In: Bres, J.; Haillet, P.P.; Mellet, S.; Nølke, H. e Rosier, L. (dirs.). Dialogisme et polyphonie. Approches linguistiques. Bruxelles: De Boeck.

BRKIC, J. e ANDERSON, N. (1988). Drafting and Interpreting Legal Documents. In: Kevelson, R. (ed.). Law and Semiotics. Vol. 2. New York: Plenum Press.

CALHOUN, C. (1996). "Introduction: Habermas and the public sphere». In: Calhoun, C. (ed.) Habermas and the Public Sphere. 4. ${ }^{\mathrm{a}}$ ed., Cambridge: MIT Press, pp. 1- 48.

CAMPS, V. (2004). «Instituiciones, agencias y mecanismos de supervisión mediática». In: CONILL SANCHO, J.; GONZÁLEZ, V. (coords.). Ética de los Medios - Una apuesta por la ciudadanía audiovisual. Barcelona: Editorial Gedisa.

CANIVET, G. e JOLY-HURARD, J. (2004). La déontologie des magistrats. Paris: Dalloz.

CANotilho, G. e MOReira, V. (2007). Constituição da República Portuguesa Anotada, vol. I. Coimbra: Coimbra Editora.

CARAPINHA, M. C. (2006). Contributos para a análise da linguagem jurídica e da interacção verbal em sala de audiências. Dissertação de Doutoramento (não publ.). Coimbra: Faculdade de Letras.

CARMO, R. do (2005). "O dever de reserva - O dever de informar: algumas achas para o debate». In: AA VV, Balanço da reforma da acção executiva. Segredo de justiça e dever de reserva (Conselho Superior da Magistratura, II Encontro Anual -2004). Coimbra: Coimbra Editora, pp. 155-162.

CARPINI, M. D. e WILliAMS, B. A. (2001). «Let Us Infotain You: Politics in the New Media Environment». In: Bennet, W. L.; Entman, R. M. (eds). Mediated politics: communication in the future of democracy. Cambridge: Cambridge University Press, pp. 160-181.

CASTELLS, M. (1999). O poder da identidade (A era da informação: economia, sociedade e cultura; v.2). São Paulo: Paz e Terra.

CHERMAK, S. M. (1995). Victims in the News. Crime and the American News Media. Boulder, San Francisco, Oxford: Westview.

CHIBNALL, S. (1977). Law-and-Order News: An Analysis of Crime Reporting in the British Press. London: Tavistock Publications.

CHRISTIE, G. C. (1964). "Vagueness and Legal Language». In: Minnesota Law Review, 48.

COHEN, J. (1997). Deliberative Democracy. Cambridge: MIT Press.

COHEN, J. (2009). "Deliberação e legitimidade democrática». In: Marques, A. (ed.). A Deliberação Pública e suas Dimensões Sociais, Políticas e Comunicativas. Belo Horizonte: Autêntica Editora.

COHEN, S. (2002). Folk Devils and Moral Panics. The Creation of the Mods and Rockers, 3. ${ }^{\mathrm{a}}$ ed. London, New York: Routledge.

COHEN, S. e YOUNG, J. (1973). The Manufature of News: Deviance, Social Problems and the Mass Media. London: Constable.

CONSELHO REGULADOR (2006). Parecer Relativo ao Anteprojecto da Proposta de Lei que Altera o Estatuto dos Jornalista - Parecer 2/2006.

CORNU, G. (2000). Linguistique Juridique. $2^{\text {a }}$. Ed. Paris: Montchrestien.

CORNU, D. (1994). Journalisme et Vérité. Genebra: Labor et Fides.

CORREIA, J. C. (2005). Sociedade e Comunicação: Estudos sobre Jornalismo e Identidades. Covilhã: UBI. 
COULTHARD, M. e JOHNSON, A. (2007). An Introduction to Forensic Linguistics. Language in Evidence. London: Routledge.

COUlthARD, M. e JOHNSON, A. (eds.) (2010). The Routledge Handbook of Forensic Linguistics. London: Routledge.

CURTIS, P. (2001). Jack the Ripper and the London press. New Haven: Yale University Press.

DOUGLAS, M. (1986). How Institutions Think. New York: Syracuse University Press.

DRYZEK, J. (2004). "Legitimacy and economy in deliberative democracy» In: Farrely, C. Contemporary Political Theory: a Reader. London: Sage.

DRYZEK, J. (2000). Deliberative Democracy and Beyond: Liberals, Critics, Contestations. Oxford: Oxford University Press.

DUBOUCHET, P. (1990). Sémiotique Juridique. Paris: PUF.

DUCROT, O. (1982). La notion de sujet parlant. In: Cahier du Groupe de Recherches sur la Philosophie et le langage, 2. Grenoble: Université de Grenoble.

DUCROT, O. (1984). Le Dire et le dit. Paris: Minuit.

DURKHeIM, É. (1977). A Divisão do Trabalho Social, Vol. 1, trad. de M. I. Freitas. Lisboa: Editorial Presença.

EAGLETON, T. (2000). Ideology: an Introduction. 7. ${ }^{\mathrm{a}}$ ed. London: Verso.

ELSTER, J. (1986). "The Market and the Forum: Three Varieties of Political Theory". In: Elster, J.; Hylland, A. (eds). Foundations of Social Choice Theory, Cambridge: Cambridge University Press, pp. 104-132.

ELSTER, J. (1998). Deliberative Democracy. Cambridge: Cambridge University Press.

ERICSON, R., BARANEK, P. e CHAN, J. (1989). Negotiating Control: A Study of News Sources. Toronto: University of Toronto Press.

ESSER, F. (1999). "Tabloidization of news. A comparative analysis of Anglo-American and German Press Journalism». In: European Journal of Communication, pp. 291-324.

FARIA, J. E. (1986). "A Reforma do Ensino Jurídico». In: Revista Crítica de Ciências Sociais, 21.

FERNANDES, P. C. (2008). "Justiça e media: legitimação pela comunicação». In: Revista do CEJ $\left(n .^{\circ} 10\right)$, pp. 311-346.

FIGUEIREDO, C. e COSTA, R. (1990). "Alta Autoridade da discórdia». In: Expresso - Suplemento A4, 27 de janeiro.

FONSECA, J. (1994). "O lugar da Pragmática na Teoria e na Análise Linguísticas». In: Pragmática Linguística. Introdução, Teoria e Descrição do Português. Porto: Colecção Linguística/Porto Editora, n. ${ }^{\circ} 5$.

FOUCAUlT, M. (1991). Vigiar e Punir: Nascimento da Prisão. 9. ${ }^{a}$ ed., trad. de L. M. P. Vassallo. Petrópolis: Vozes.

FOX, R. L. e SICKEL, R. V. (2001). Tabloid Justice: Criminal Justice in an Age of Media Frenzy. London: Lynne Rienner Publishers Boulder.

FRANKLIN, B. (1997). Newszak \& News Media. London: Hodder Arnold.

FRASER, N. (1996). "Rethinking the public sphere: a contribution to the critique of actually existing democracy» In: Calhoun, C (ed.) Habermas and the Public Sphere. 4. ${ }^{a}$ ed., Cambridge: MIT Press, pp. 109-142.

FRIEDMAN, L. M. (1964-1965). Law and its Language. In: George Washington Law Review, p. 33.

FUENTES GONZÁLEZ, D. (1997). Algunas aportaciones de la sociolingüística al campo del derecho. In: Delgado León, F.; Calero Vaquera, M. L. e Osuna García, F. (eds.), (1998). 
Actas del II Simposio de Historiografía Lingüística. Córdoba: Servicio de Publicaciones de la Universidad de Córdoba.

GALVÃO TELLES, I. (2000). Introdução ao Estudo do Direito. Vol. II. 10 ${ }^{\mathrm{a}}$ ed. Coimbra: Coimbra Editora.

GARAPON, A. (1998). O guardador de promessas. Lisboa: Instituto Piaget.

GARLAND, D. (2001). The Culture of Control. Oxford: Oxford University Press.

GARMENT, S. (1991). Scandal: The Culture of Mistrust in American Politics. New York: Times Books.

GEYH, C. G. (2006). Preserving Public Confidence in the Courts in an Age of Individual Rights and Public Skepticism. http://ssrn.com/abstract=933699: Indiana University School of Law-Bloomington.

GIBBONS, J. (ed.) (1994). Language and the Law. London: Longman.

GIBBONS, J. (2003). Forensic Linguistics. An Introduction to Language in the Justice System. Oxford: Blackwell.

GIBBONS, J. e TURELL, M. T. (eds.) (2008). Dimensions of Forensic Linguistics. Amsterdam: John Benjamins Publishing Company.

GOLDMAN, L. (1994). Accident and absolute liability in anthropology. In: Gibbons (ed.). Language and the Law. London: Longman.

GOODRICH, P. (1987). Legal discourse. Studies in Linguistics, Rhetoric and Legal Analysis. London: Macmillan.

GRABER, D. A. (1980). Crime News and the Public. New York: Praeger.

GREER, C. e JEWKES, Y. (2005). "Extremes of Otherness: Media Images of Social Exclusion». In: Social Justice, 32 (1), pp. 20-31.

GREIMAS, A. J. (1976). Analyse sémiotique d'un discours juridique. In Greimas, A. J.. Sémiotique et sciences sociales. Paris: Seuil.

GRICE, P. (1975). Logic and Conversation. In: Cole, P.; Morgan, J. L. (eds.). Syntax and Semantics 3: Speech Acts. New York: Academic Press.

GUTMANN, A. e THOMPSON, D. (2007), "O que significa democracia deliberativa", In: Revista Brasileira de Estudos Constitucionais, Belo Horizonte, Ed. Fórum, 2007, pp. 17-78.

HABERMAS, J. (1996). Between Facts and Norms. Contributions to a Discourse Theory of Law and Democracy, Cambridge, MA: MIT Press.

HABERMAS, J. (1996), "Three Normative Models of Democracy» In: Benhabib, S. (ed.) Democracy and Difference. Princeton, NJ: Princeton University Press.

HABERMAS, J. (1997). Direito e Democracia - Entre facticidade e validade, vol. II. Rio de Janeiro.

HABERMAS, J. (1998). The Structural Transformation of the Public Sphere: An Inquiry into a Category of Bourgeois Society, 9. ${ }^{\mathrm{a}}$ reimp., trad. de T. Burger. Cambridge, MA: MIT Press.

HABERMAS, J. (2002). "Prefacio a la Nueva Edición Alemana de 1990". In: Historia y Crítica de la Opinión Pública: La Transformación Estructural de la Vida Pública, trad. de F. Gil Martín, $7^{\text {a }}$. reimp., Barcelona: Gustavo Gilli.

HALl, S., CRITCHER, C., JEFFERSON, T., CLARKE, J. e ROBERTS, B. (1978). Policing the Crisis: Mugging, the State, and Law and Order, London: The MacMillan Press.

HARRIS, S. (1994). Ideological exchanges in British magistrates courts. In: Gibbons, J. (ed.). Language and the Law. London: Longman.

HJARVARD, S. (2008). "The Mediatization of Society: a Theory of the Media as Agents of Social and Cultural Change». In: Nordicom Review 29, 2, pp. 105-134. 
HOEY, M (1985). "The Statute as Discourse and the Lawyer as Linguist». In: Hall, R. A. J. (ed.) The Eleventh LACUS Forum 1984. Columbia: Hornbeam Press.

HONNETH, A. (1995). The Fragmented World of the Social: Essays in Social and Political Philosophy. New York: SUNY Press.

HUTCHINGS, P. (1999). «Spectacularizing crime: ghostwriting the law». In: Law and Critique, 10: pp. 27-48.

JACKSON, B. S. (1995). Making Sense in Law. Linguistic, Psychological and Semiotic Perspectives. Liverpool: Deborah Charles Publications.

JALALI, C. (2005). "Nova governação nova cidadania? Os cidadãos e a política em Portugal». In: Revista de Estudos Politécnicos, vol. II, n. ${ }^{\circ} 4$.

JIMÉNEZ, F. J. (1994). «Posibilidades y limites del escandalo politico como una forma de control social». In: REIS Revista Española de Investigaciones Sociológicas, pp. 7-36.

KELSEN, H. (1934). "The pure theory of law, its methods and fundamental concepts". In: Law Quarterly Review, n. ${ }^{\circ} 50$.

KISSELER, L., e HEIDEMANN, F. (2006). «Governança pública: novo modelo regulatório para as relações entre Estado, mercado e sociedade?». In: Revista da Administração Pública, 40 (3), Rio de Janeiro, Maio/Junho.

LAMBERT, P. (2004). "Le devoir de réserve et les notions voisines». In: AA VV. Actes de la Table Ronde organisée par l' Institut d'Études sur la Justice, le 17 octobre 2003, Bruxelles: Bruylant, pp. 9-19.

LEVI, J. N. e WALKer, A. G. (eds.) (1990). Language in the Judicial Process. New York: Plenum Press.

MACHADO, H. e SANTOS, F. (2009). A moral da justiça e a moral dos media: Julgamentos mediáticos e dramas públicos (Oficina do CES $n .^{\circ} 333$ ). Coimbra: CES.

MACHADO, H. e SANTOS, F. (2008). Crime, drama e entretenimento. O caso Maddie e a meta-justiça popular na imprensa portuguesa (Oficina do CES n. ${ }^{\circ}$ 308). Coimbra: CES.

Machado, J. (2002). Liberdade de Expressão. Dimensões constitucionais da esfera pública no sistema social. Coimbra: Coimbra Editora.

MACHADO, J. B. (2002). Introdução ao Direito e ao Discurso Legitimador. (13 $3^{\mathrm{a}}$ reimp.) Coimbra: Almedina.

MALEY, Y. (1994). The Language of the Law. In: Gibbons, J. (ed.). Language and the Law. London: Longman.

MANIN, B. (1987). "On Legitimacy and Political Deliberation». In: Political Theory, 15, pp 338-368.

MANSBRIDGE, J. (1999). "Everyday talk in deliberative system» In: Macedo, S. (ed.). Deliberative Politics: Essays on Democracy and Disagreement. New York: Oxford University Press.

MARMOR, A. (2008). "What Does the Law Say?»In: Analisi e diritto 2007. Ricerche di giurisprudenza analitica. Torino: G. Giappichelli Editore.

MASCARENHAS, Ó. (1998) "Por uma carta 98 da auto-regulação». In: AAVV. $3 .^{\circ}$ Congresso dos Jornalistas Portugueses - Conclusões, teses, documentos, Lisboa, Comissão Executiva do III Congresso dos Jornalistas Portugueses.

MASON, P. (2006) «Lies, distortion and what doesn't work: monitoring prison stories in the British media». In: Crime Media Culture, 2 (3), pp. 251-267.

MATHIESEN, T. (1995). "The eagle and the sun: on panoptical systems and mass media in modern society». In: Ericson, R. (ed.) Crime and the Media. Aldershot, Brookfield USA, Singapore, Sydney: Dartmouth, pp. 333-350. 
MATHIESEN, T. (2004). Essays on the creation of Acquiescense in Modern Society, Winchester: Waterside Press.

MATHIESEN, T. (2006). Prison on Trial, $3^{\mathrm{a}}$. ed., Winchester: Waterside Press.

MATOS, F. A. (2011). Responsabilidade Civil por Ofensa ao Crédito ou ao Bom Nome. Coimbra: Almedina.

MESQUITA, J. (1998). "Aprofundar a autonomia", In: AAVV. 3. ${ }^{\circ}$ Congresso dos Jornalistas Portugueses - Conclusões, teses, documentos. Lisboa: Comissão do III Congresso dos Jornalistas Portugueses.

MOREIRA, V. (1997). Auto-Regulação Profissional e Administração Pública. Coimbra: Almedina, 1997.

NEWBURN, T. e JONES, T. (2007). "Symbolizing crime control». In: Theoretical Criminology, 11(2), pp. 21-243.

OLSSON, J.(2004). Forensic Linguistics. An Introduction to Language, Crime and the Law. London: Continuum.

PAIXÃO, B. (2010). O escândalo político em Portugal (1991-1993 e 2002-2004). Coimbra: Minerva.

PATON, W. R. (1922). Polybius: The Histories, Volume III, Books 5-8 (Loeb Classical Library). London: Heinemann.

PRATT, J. (2007). Penal Populism, London, New York: Routledge.

PUTMAN, E. (1997). "Éthique des affaires et déontologie des professions d'affaires: réflexions sur la morale des marchands». In: BERGEL, J-L. (org.). Droit et Déontologies Professionnelles. Aix-en-Provence: Librairie de l'Université.

RAWLS, J. (1971). A Theory of Justice. Harvard: Harvard University Press.

RAWLS, J. (2001). O Direito dos Povos. São Paulo: Martins Fontes.

RIVERA BEIRAS, I. (2003). "State form, labor market and penal system: the new punitive rationality in context». In: Punishment Society, 7(2), pp. 167-182.

SANDERS, L. (1997). "Against deliberation». In: Political Theory, 25, pp. 347-376.

SANTOS, B. S. et al. (2009). A Justiça Penal: Uma Reforma em Avaliação. Coimbra: Centro de Estudos Sociais da Faculdade de Economia da Universidade de Coimbra.

SCHLESINGER, P. e TUMBER, H. (1994). Reporting Crime: The Media Politics of Criminal Justice. Oxford: Clarendon Press.

SCHLESINGER, P., TUMBER, H. e Murdock, G. (1995). "The media politics of crime and criminal justice». In: ERICSON, R. (coord.) Crime and the Media. Aldershot, Brokfield USA, Singapore, Sydney: Dartmouth, pp 397-420.

SCHUDSON, M. (1978). Discovering the news: a social history of American newspapers. New York: Basic Books.

SCHULZ, W. (2004). "Reconstructing Mediatization as an Analytical Concept». In: European Jounal of Communication Vol 19 (1), pp. 87-101.

SCHUMPETER, J. A. (1994). Capitalism, Socialism, and Democracy. London: Routledge.

SERRANO, E. (2007). "Pensar a regulação dos media numa sociedade em mudança». In: Comunicação e Sociedade ("Regulação dos media em Portugal»), vol. 11, Braga.

SHAPIRO, I. (1999). "Enough of deliberation: politics is about interest and power". In: Macedo, S. (ed.), Deliberative Politics: Essays on Democracy and Disagreement. New York: Oxford University Press.

SHETREET, S. e DESCHÊNES, J. (eds) (1985). Judicial Independence; the contemporary debate. Amsterdam: Martinus Nijhoff. 
SILVA, A. S., (2007). "A hetero-regulação dos meios de comunicação social». In: Comunicação e Sociedade, vol. 11, Braga.

SILVA, V. J. (2006). "Ordem e desordem jornalística». In: Diário de Notícias, 29 de Março.

SILVEIRINHA, M. J. (2004). Identidades, Media e Política: O Espaço Comunicacional nas Democracias Liberais, Lisboa: Livros Horizonte.

SILVEIRINHA, M. J. (2005). "Democracia deliberativa e reconhecimento: repensar o espaço político». In: Correia, J. C. Comunicação e Política. Covilhã: UBI.

SOURIOUX, J-L e LERAT, P. (1975). Le langage du droit. Paris: PUF.

STOFFEL-MUNCK, P., (1997). "Déontologie et moral». In: Bergel, J-L. (org.), Droit et Déontologies Professionnelles. Aix-en-Provence: Librairie de l'Université.

STYGALL, G. (2010). "Legal writing: complexity. Complex documents/average and not-so-average readers". In: Coulthard, M.; Johnson, A. (eds.) (2010). The Routledge Handbook of Forensic Linguistics. London: Routledge.

SURETTE, R. (2010). Media, crime, and criminal justice: images, realities and policies. $4 .{ }^{a}$ ed. Belmont: Wadsworth.

THOMAS, J. (1997). Judicial Ethics in Australia. Sydney: Law Book Co.

THOMPSON, J. (2005). "The new visibility". In: Theory, Culture E Society, 22(6),pp. 31-51.

THOMPSON, J. B. (2002). O escândalo político: poder e visibilidade na era da mídia. Petrópolis: Editora Vozes.

THORNTON, G. C. (1996). Legislative Drafting. London: Butterworth.

THUSSU, D. K. (2007). News as entertainment: the rise of global infotainment. London: Sage.

TIERSMA, P. M. (1993). «Linguistic Issues in the law». In: Language, 69, pp. 113-137.

TIERSMA, P. M. (2000). Legal Language. Chicago: The University of Chicago Press.

VALIER, C. (2002). Theories of Crime and Punishment. Harlow, New York: Longman.

VAN DIJK, T. A. (1990). La Noticia como Discurso: Comprensión, Estructura y Producción de la Información, Paidós: Barcelona.

VAN DIJK, T. A. (2005). Discurso, Notícia e Ideologia: Estudos na Análise Crítica do Discurso, trad. de Z. P. Coelho, Porto: Campo das Letras.

VAN OMMESLACHE, P. (1995) “L'autorégulation». In: AAVV, L'Autorégulation. Bruxelas: Bruylant.

VERDUSSEN, M. (2004). "Le devoir de réserve au regard de la jurisprudence de la Cour Européenne des Droits de l'Homme». In: AA VV, Actes de la Table Ronde organisée par l' Institut d' Études sur la Justice, le 17 Octobre 2003. Bruxelles: Bruylant, pp. 21-31.

VILlEY, M. (1974). "Préface». In: Archives de Philosophie du Droit, Tome XIX.

VILLEY, M., KALINOWSKI, G. e GARDIES, J-L. (1974). "Indicatif et impératif juridiques. Dialogue à trois voix". In: Archives de Philosophie du Droit, Tome XIX.

VIRALlY, M. (1966). "Le phénomène juridique». In: Revue de Droit Public.

WACQUANT L. (2001). "How penal common sense comes to Europeans: notes on the transatlantic diffusion of neoliberal doxa». In: European Societies, 1 (3), pp. 319-352.

WEICHER, M. E. e GOLDSCHMIDT, J. (2007). "The Expansion of the First Amendment in Judicial Elections: Another Cause for Reform». In: Loyola University Chicago Law Journal, pp. 833-894.

WEICK, K. E. (1995). Sensemaking in Organizations. London: Sage. 
WIENER, J. (1988). Papers for the millions; the new journalism in Britain, 1850-1914. New York: Greenwood.

WIIO, O. A. (1995). "Organizational communication. Contingent views». In: Goldhaber G.M.; Barnett G. A. (eds.). Handbook of Organizational Communication. Norwood: Ablex.

WILliAMS, G. (1945). Language and the Law (artigo em 5 partes). In: The Law Quarterly Review 61 (4 partes) e 62 (5. ${ }^{\mathrm{a}}$ parte).

WOLTON, D. (1995). "As contradições do espaço público mediatizado". In: Revista de Comunicação e Linguagens, 21-22, pp. 167-188.

YOUNG, I. M. (2000). Inclusion and Democracy. Oxford: Oxford University Press. 